\title{
Low vision services for vision rehabilitation in the United Kingdom
}

\author{
L E Culham, B Ryan, A J Jackson, A R Hill, B Jones, C Miles, J A Young, C Bunce, \\ A C Bird
}

\begin{abstract}
Aim: Little is known about the distribution and methods of delivery of low vision services across the United Kingdom. The purpose of this study was to determine the type and location of low vision services within the UK.

Methods: Survey by means of a 29 point postal questionnaire, followed when necessary by a five point telephone questionnaire. All known potential providers of low vision services ( $n=2539$ ) including hospitals ( $n=277)$, optician/optometry practices ( $n=1683$ ), social services (n $=177$ ), voluntary groups ( $\mathrm{n}=190)$, specialist teachers ( $\mathrm{n}$ $=205)$, and universities $(n=6)$ were surveyed. For each service provider, the type, magnitude, and geographical location were determined. The distribution of services across the United Kingdom and the ratio of providers to population density of people with a visual impairment were mapped using the Geographic Information System (GIS).

Results: Data were obtained on 1945 (77\%) service providers: $1679(66 \%)$ responded to the postal questionnaire and $266(11 \%)$ to the telephone questionnaire. Of all respondents, $59 \%$ ( $n=1135$ ) offer some form of help to people with a visual disability, of which $26 \%(n=497)$ only sell magnifiers and $33 \%(n=638)$ provide low vision services. It is estimated that in total just under 155000 low vision consultations are offered annually, the bulk of which are provided by hospital eye departments. The distribution was geographically uneven and there appears to be scarcity in some areas.

Conclusion: When compared to the probable number of people with a visual impairment in the UK there are apparent inadequacies in service provision in terms of distribution, magnitude, and coordination. The results highlight a need to review current services.
\end{abstract}

$\mathrm{B}$ ilateral visual loss impacts not only on an individual's ability to undertake vision dependent tasks associated with daily living but on the psychological and emotional state. Adapting to visual loss, which in most cases is of late onset and progressive, involves developing strategies whereby residual vision can be optimised while, at the same time, coming to terms with the psychology of bereavement. This adaptive process, visual rehabilitation, may involve the acquisition of optical and non-optical aids and appliances, the development of novel handling and viewing strategies, and modifications to the visual environment including the use of new lighting and contrast enhancement techniques. This is likely to be made much easier if those affected by visual impairment have access to comprehensive and easily accessible services designed to cater for visual rehabilitation needs. These services are now internationally referred to as low vision services.
Undoubtedly, the highly motivated, able bodied, and intellectually alert patient with access to, among other things, the internet may very well utilise the concept of self help to obtain solutions to many of their rehabilitative needs. However, this may not be the case for the increasing number of elderly people who frequently suffer from other disabilities and often live alone. Approximately $85 \%$ of those known to be visually impaired have useful residual vision ${ }^{1}$ and could benefit from visual rehabilitation ${ }^{2-4}$ as opposed to rehabilitation involving alternative sensory stimulation (braille or audio tape, etc). Within the United Kingdom, various components of low vision services are provided by a variety of professionals (optometrists, rehabilitation officers, social workers, ophthalmologists, orthoptists, nurses, etc) working for a range of agencies (statutory and voluntary) at a varied set of locations (hospitals, general practices, community centres, resource centres). In this study, we seek to determine the type and location of services across the UK.

\section{MATERIALS AND METHODS \\ Design}

A postal questionnaire, consisting of 29 questions, was distributed to all potential low vision service providers across the UK. A telephone questionnaire with five principal points was resorted to when providers failed to respond to either the initial questionnaire or to follow up postal correspondence. Before the formal release of the postal questionnaire, which was designed by the authors of the study, it was vetted by 50 potential users and piloted on a sample of 20 service providers. Similarly, the telephone questionnaire was also piloted before use $(n=20)$. A broad range of key aspects about low vision services was investigated, including access to services, professional staff/agencies involved, information on the rehabilitation undertaken, and sources of funding. In this paper, we will report on the main findings relating to the type, location, and level of services provided.

\section{Subjects}

Six potential service provider groups were identified using existing published directories. This source proved deficient, and it was necessary to develop an independent database. The provider groups included hospitals with eye departments (HED); social services/social work departments (SSD); opticians/optometry practices (OP); local societies/voluntary organisations for people with visual impairment (VO); specialist teachers (ST), and universities/colleges with optometry/optical dispensing courses (UC).

\section{Questionnaire presentation and return}

Data were collected between October 1997 and June 1998. Three to 5 weeks after the initial postal questionnaire was dispatched, a second was sent to all non-respondents. Six to 8 weeks after the initial contact, telephone calls were made to non-respondents to encourage return of the questionnaire. Six 


\begin{tabular}{|c|c|c|c|c|}
\hline Type of provider & $\begin{array}{l}\text { Number of postal } \\
\text { questionnaires sent }\end{array}$ & Postal response & $\begin{array}{l}\text { Telephone } \\
\text { response }\end{array}$ & Overall responses \\
\hline HED & 277 & $223(81 \%)$ & 54 (19\%) & $277(100 \%)$ \\
\hline SSD & 177 & $146(82 \%)$ & 31 (18\%) & 177 (100\%) \\
\hline VO & 190 & $148(78 \%)$ & $42(22 \%)$ & $190(100 \%)$ \\
\hline OP & 1683 & $960(57 \%)$ & $130(8 \%)$ & $1090(65 \%)$ \\
\hline ST & 205 & $196(96 \%)$ & $9(4 \%)$ & 205 (100\%) \\
\hline UC & 6 & $6(100 \%)$ & $0(0 \%)$ & $6(100 \%)$ \\
\hline Not specified & 1 & $0(0 \%)$ & $0(0 \%)$ & $0(0 \%)$ \\
\hline Total & 2539 & $1679(66 \%)$ & $266(11 \%)$ & 1945 (77\%) \\
\hline
\end{tabular}

\begin{tabular}{|c|c|c|c|c|c|}
\hline $\begin{array}{l}\text { Type of } \\
\text { provider }\end{array}$ & No response & $\begin{array}{l}\text { No service } \\
\text { provided }\end{array}$ & $\begin{array}{l}\text { Providers that } \\
\text { only sell low } \\
\text { vision aids }\end{array}$ & $\begin{array}{l}\text { Providers of } \\
\text { low vision } \\
\text { services }\end{array}$ & $\begin{array}{l}\text { Total providing } \\
\text { some form of help } \\
\text { (column } 4+ \\
\text { column 5) }\end{array}$ \\
\hline HED & $0(0 \%)$ & 97 (35\%) & $0(0 \%)$ & $180(65 \%)$ & $180(65 \%)$ \\
\hline SSD & $0(0 \%)$ & 82 (46\%) & $5(3 \%)$ & $90(51 \%)$ & $95(54 \%)$ \\
\hline vo & 1 (1\%) & 98 (52\%) & $44(23 \%)$ & 47 (25\%) & 91 (48\%) \\
\hline OP & $6(1 \%)$ & $390(36 \%)$ & $448(41 \%)$ & $246(23 \%)$ & 694 (64\%) \\
\hline ST & 0 (0\%) & 135 (66\%) & $0(0 \%)$ & $70(34 \%)$ & $70(34 \%)$ \\
\hline UC & $0(0 \%)$ & $1(17 \%)$ & $0(0 \%)$ & $5(83 \%)$ & $5(83 \%)$ \\
\hline Total & 7 (0\%) & $803(41 \%)$ & 497 (26\%) & $638(33 \%)$ & 1135 (59\%) \\
\hline
\end{tabular}

weeks later non-respondents were contacted by telephone and asked to participate in the telephone questionnaire.

Optician/optometry practices represented the largest potential provider group $(\mathrm{n}=1683)$ and a notable proportion $(\mathrm{n}=$ $723 ; 43 \%$ ) did not respond to the two postal questionnaires. The subsequent telephone questionnaire, administered to an $18 \%(\mathrm{n}=130)$ random sample of OPs that did not initially respond, found that only a small percentage $(n=22 ; 17 \%)$ offered low vision services. This sample suggested that OPs would only account for a very small proportion of the total providers, and the decision was made not to complete the telephone questionnaire with this group.

\section{Data management and analysis}

Data entry onto an Access 97 database was undertaken by two individuals working to a protocol to ensure consistency. For purposes of validation, data were double entered; a low error rate $(0.9 \%)$ was recorded and data amended accordingly. Analysis of the type and extent of services were performed using STATA software (Stata Statistical Software: Release 5.0 College Station, TX, USA: Stata Corporation).

Plotting the location of service providers across the UK was achieved using Geographic Information Systems (GIS) technology ${ }^{5}$ together with population ${ }^{6}$ and boundary data. ${ }^{7}$ Postcodes were checked against the Post Office's postcode address file, which is the definitive listing of all postal delivery addresses in the UK. In order to relate service provision with the demands of the population, the numbers of people with a visual impairment based on RNIB prevalence rates $^{8}$ were mapped according to local authority.

\section{Availability of services}

Services were categorised into one of three groups: 1, no service; 2, sell magnifiers only-that is, without assessment or professional support; 3 , low vision services, including the prescribing of low vision aids (LVAs) and/or support, such as counselling or training. No assessment was made of the completeness or quality of services, although inferences could be drawn from the information provided.

In order to determine the magnitude of services, the total number of consultations offered annually across the UK was estimated. This calculation was achieved by adding together the service providers' own estimate of the number of consultations they had undertaken. All appointments, for the purpose of prescribing LVAs, training, or counselling were included in this calculation.

\section{RESULTS \\ Response rate}

In total, 2539 potential low vision service providers were identified and, of these, 1679 (66\%) completed questionnaires. With the additional data collected from 266 (11\%) telephone questionnaires, the overall response rate was $77 \%(n=1945)$ (see Table 1). This represents a 100\% response from all provider groups other than the OPs that recorded a response rate of only $65 \%(n=1090)$. Telephone contact with the nonrespondents in the OP group indicated that only a relatively small proportion of those who responded provided any low vision service $(17 \%)$. Projections thus indicate that approximately 101 of non-responding OPs may offer some form of low vision service.

\section{Availability of services}

Of the 1945 respondents, $41 \%(n=803)$ offer no service, $26 \%$ ( $\mathrm{n}=497)$ only sell magnifying devices, and 33\% ( $\mathrm{n}=638)$ provide low vision services (Table 2 ).

The estimate indicates that just under 155000 appointments for low vision services are offered annually. This figure excludes any projection from the non-respondents, which was found to be small. HEDs (that is, 180 service points) were the largest provider of services with $65 \%$ of the total annual appointments. Although other provider groups accounted for 


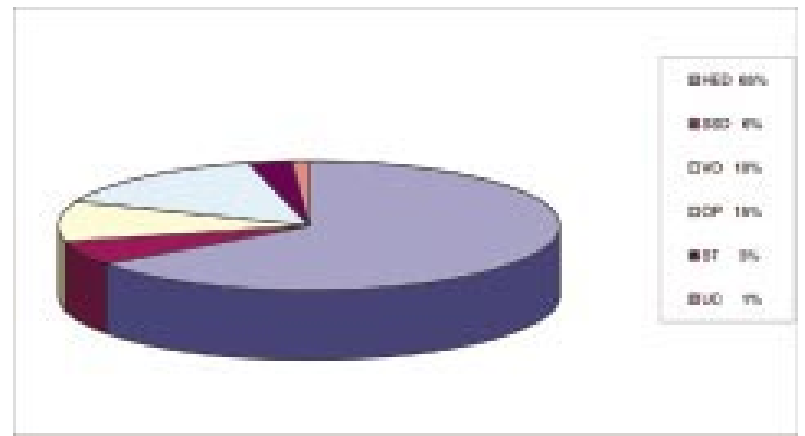

Figure 1 Percentage of appointments offered by provider type $(\mathrm{n}=$ 155 000). HED, hospitals with eye departments; SSD, social services/social work departments; VO, local societies/voluntary organisations for people with visual impairment; $\mathrm{OP}$ opticians/optometry practices; ST, specialist teachers, UC, universities/colleges with optometry/optical dispensing courses.

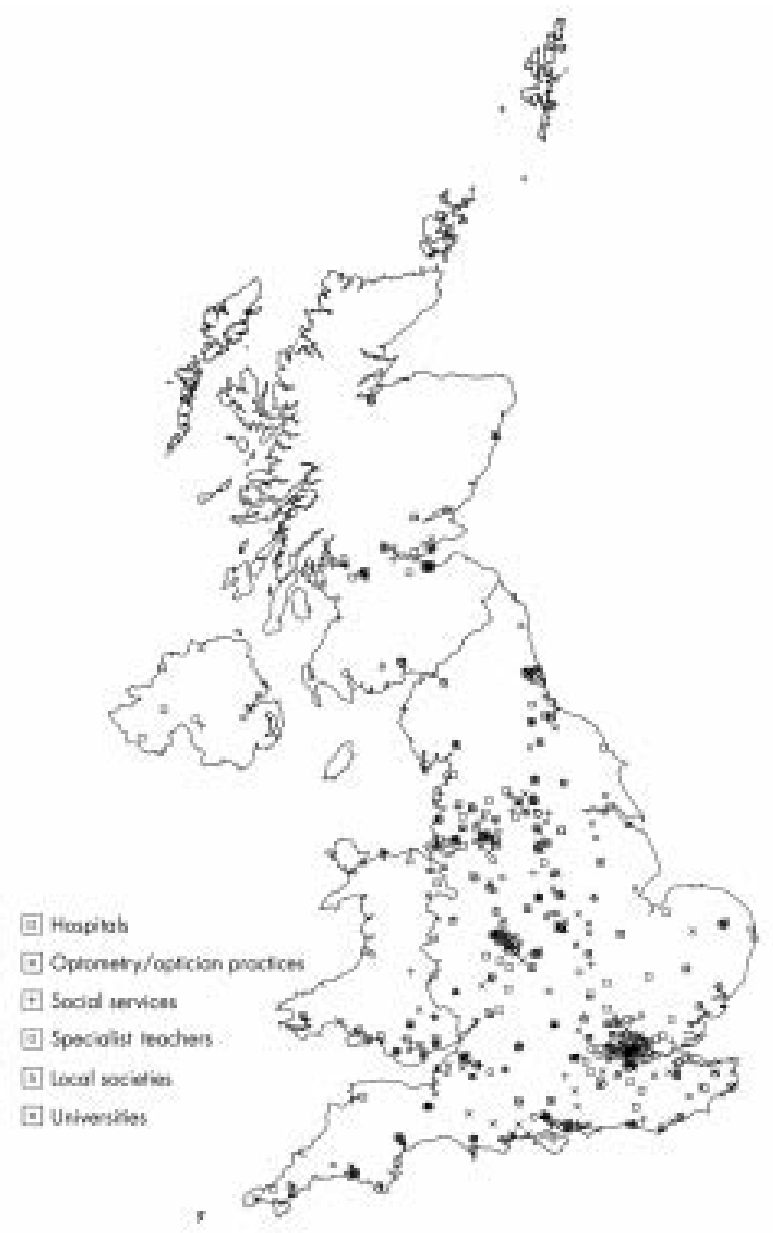

Figure 2 Location of low vision services in the UK.

a larger number of service delivery points (that is, 458) they undertake less low vision work (Table 2 and Fig 1 ).

\section{Geographical location of service providers}

The distribution of service delivery points, classified according to service provider, throughout the UK is illustrated in Figure 2. As expected, services providers are clustered in urban areas where population densities are highest, while rural regions are less well served.

Figure 3 shows the providers' location against the estimated visually impaired population mapped according to local

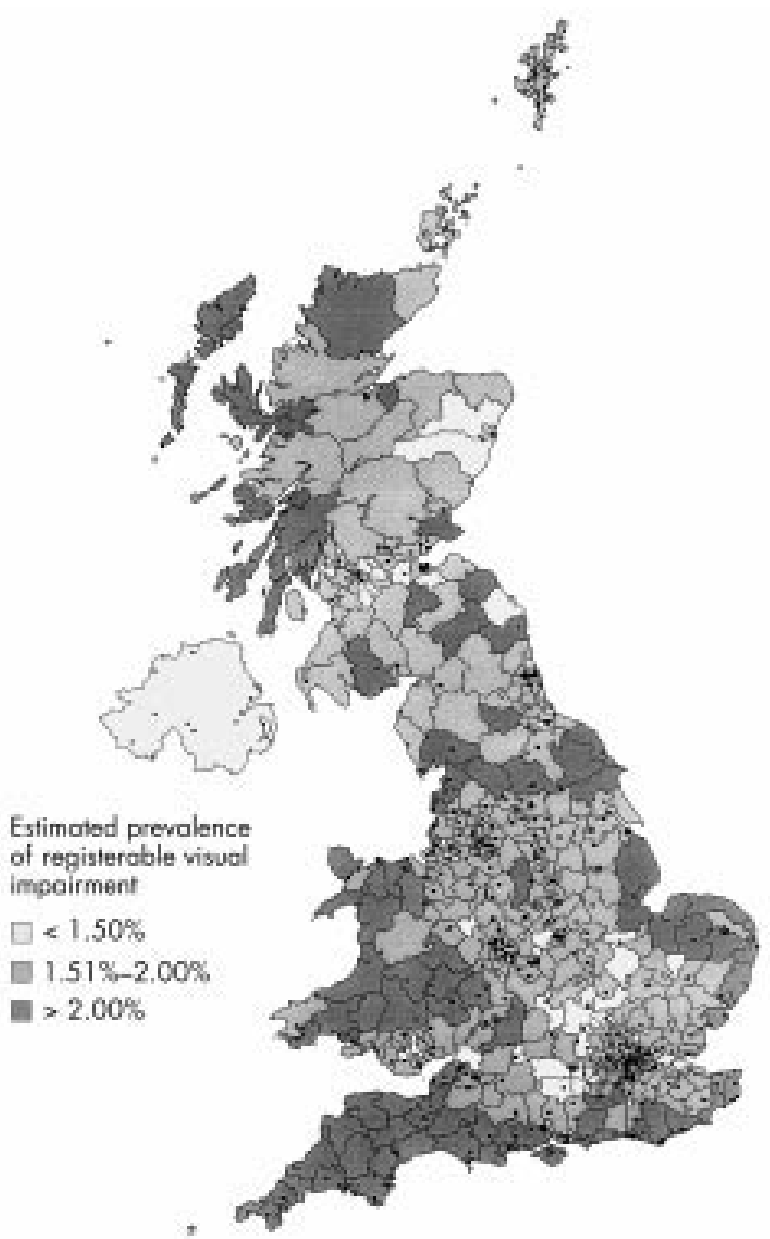

Figure 3 Location of low vision service providers against the visually impaired population according to local authority boundaries. Note: RNIB estimates of registerable visual impairment ${ }^{8}$ calculated using coefficients derived for different age groups from the survey of the needs of blind and partially sighted adults. 'The coefficient for each age group was multiplied by the estimates of the population by age within each local authority. Registration and health and social service board boundaries are not available for Northern Ireland (NI); an estimate of the prevalence of visual impairment was made for the whole of NI by the RNIB's NI office.

authority boundaries. Where prevalence of visual impairment is highest but the general population is smaller, the number of service providers is relatively low. Conversely, in cities prevalence is moderate but the general population is larger and services are more available.

\section{DISCUSSION}

Given the 100\% response rates recorded from the service providers responsible for offering more than $85 \%$ of service delivery (HO, SSD, VO, ST, OC), it is likely that our survey gives an accurate indication of current provision of low vision services in the UK. The results from the follow up telephone interviews with a random sample of non-responding OPs indicated that less than $17 \%$ of these provided any form of low vision service; hence, it is unlikely that the non-respondents would significantly bias the findings. The response rate compares favourably with similar postal surveys-that is, 53\% for a regional survey in Wisconsin, USA $^{9}$ and $75 \%$ for a national US survey. ${ }^{10}$

One of the main questions facing those planning and commissioning low vision services relates to the demand for services and the current provision. Government statistics show that in 1994 in the UK, 315782 people were on the blind or 
partially sighted registers, and there are currently over 35000 individuals newly registered each year. ${ }^{11-14}$ It is widely agreed that this figure underestimates the true extent of registerable visual impairment in the population by $2-3$-fold. ${ }^{15-17}$ Furthermore, there are many with a sight impairment who do not warrant registration but who could be helped by low vision services. Thus, over one million people resident in the UK may benefit from low vision support, approximately 70000 of whom are newly impaired, but the current system offers no more than 155000 appointments per annum. Our professional experience is that because of progressive visual loss, changing life circumstances, and the need to have optical appliances updated and repaired, low vision services must provide regular review. On this basis the assumption could be made that a visually impaired person requires a minimum of three appointments. This would allow for an individual needs assessment, refraction, prescription of devices, instruction, plus two follow up appointments to ensure that the visual demands have been met. Over a period of time, as people's requirements change and devices need to be replaced or repaired, there should be the capacity in the system to cope with other demands. In addition, new aids, particularly high tech video based devices, are becoming available. ${ }^{18}$ Current limited resources will be further strained since these expensive devices are time consuming to demonstrate and extensive patient education is essential. More epidemiological data are, however, required if clearer estimates are to be made of the numbers of individuals likely to benefit from low vision service provision. A comprehensive assessment of need would assist policymakers with the planning of future low vision services. Using the data available in this study, it appears that there is substantial underprovision.

On the basis of the present evidence there is a clear need to expand the service. The number of appointments has increased over the years, as shown by a survey undertaken 20 years ago, when only 35000 consultations took place annually. ${ }^{19}$ Looking to the future, the need to provide adequate services becomes more pressing because we know that the magnitude of the problem will grow. Age is a risk factor for vision loss, ${ }^{20}{ }^{21}$ the population is ageing, ${ }^{22}$ and there is slow advance in medical treatment for the main cause of blinding eye disease (age related maculopathy). ${ }^{23}$ However, one of the main difficulties in determining the future rehabilitation needs is that there is no model of care that is considered ideal-for example, it is not known how many appointments are optimal, which professions should be involved, and what techniques should be employed. Indeed, to date no comparisons of different models of care for success or cost effectiveness have been published. The availability of the more comprehensive methods of visual rehabilitative care, better and more low vision hardware, and training programmes will also increase the demands for services. Further work to identify the kind of services required would be immensely helpful.

The location of providers is also key in planning an accessible service. This study has shown that services are unevenly distributed across the country. Particularly notable is the scarcity of services in coastal and rural areas where, because of the migration of the elderly, the proportion of the population with visual impairment is often high. Regional variations will be considered in future analysis of these data. It is clear, however that lack of local services in some areas means that those wishing to access services have to travel long distances to avail themselves of help. Many of those requiring service provision will also find access to remote services difficult as mobility may be impeded by a combination of medical problems and an absence of carers. In summary, services must be provided which are of adequate quality, accessibility, and magnitude.

Currently, hospital eye departments undertake the greatest amount of low vision work (that is, 65\%), which is not surprising since the majority of funding for NHS provision, including the "no charge loan" of LVAs and ophthalmological intervention, is provided within the hospital environment. However, a high proportion of the optical requirements of people with visual impairment can be met by relatively simple optical devices, ${ }^{3}{ }^{4}$ which could be supplied by non-hospital based professionals. This study identifies a means by which improvement of the service can be achieved. At present only one third of potential providers make an active contribution to low vision services, the majority either do not provide this service at all or simply sell magnifiers without professional support. This represents an enormous underutilisation of potential resources that warrants further investigation. Of particular note is the large number of OPs, which are staffed by professionals with appropriate training and expertise, who do not offer a service. Recruitment of such personnel either into the hospital or in close contact with medical ophthalmic care would contribute substantially to the service.

Concern about low vision services has led to recent initiatives ${ }^{24} 25$ that have attempted to address some of the perceived problems. The results from this national survey provide evidence that supports the concept of the current inadequacies in the system and highlights the areas that require further research in order to provide the essential information on which future low vision service provision should be planned.

\section{ACKNOWLEDGEMENTS}

Funding: Grants from Royal National Institute for the Blind and Moorfields Eye Hospital NHS Trust.

Proprietary interests: None.

Part of this paper was presented at the International Conference on Low Vision, New York, 1999.

We would like to thank Helen Masey and Jo Rideall for data collection and management and Andrew Jacks for psychological evaluation of the questionnaire. Also, grateful thanks to the Association of Optometrists and the General Optical Council for allowing access to their data files, and to all those individuals who took part in the survey.

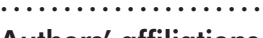

L E Culham, C Miles, A C Bird, Moorfields Eye Hospital, London, UK L E Culham, C Bunce, A C Bird, Institute of Ophthalmology, London, UK

B Ryan, The Royal National Institute for the Blind, London, UK A J Jackson, The Royal Victoria Hospital/Queens University, Belfast University of Ulster, UK

A R Hill, Oxford Eye Hospital/Oxford University, Oxford, UK

B Jones, Independent service user

J A Young, Edinburgh College of Art/Heriot-Watt University, Edinburgh, UK

Correspondence to: Dr Louise Culham, Moorfields Eye Hospital, 162 City Road, London EC 1V 2PD, UK; louise.culham@moorfields.nhs.uk

Accepted for publication 19 December 2001

\section{REFERENCES}

1 Bruce I, McKennell A, Walker E. Blind and partially sighted adults in Britain: the RNIB survey. London: HMSO, 1991.

2 Leat S, Fryer A, Rumney N. Outcome of low vision aid provision: the effectiveness of a low vision clinic. Optom Vis Sci 1994;71:199-206.

3 Shuttleworth GN, Dunlop A, Collins JK, et al. How effective is an integrated approach to low vision rehabilitation? Two year follow up results from south Devon. Br J Ophthalmol 1995;79:719-23.

4 Watson GR, DeL'Aune W, Long S, et al. Veterans' use of low vision devices for reading. Optom Vis Sci 1997;74:260-5.

5 Burrough PA, McDonnell RA. Principles of geographical information systems. Oxford: Oxford University Press, 1998.

6 UK Census of Population from the Manchester Information Datasets and Associated Data Service (MIDAS), 1991.

7 Census of Population for Local Authorities and Health Authorities/Health Boards from the United Kingdom Boundary Outline and Reference Database for Education and Research Study (UKBORDERS), 1991.

8 Royal National Institute for the Blind. Website. 1999.

9 Nelipovich M, Kossick R, Flax ME. Survey of low vision services in Wisconsin. J Vis Rehab 1991;5:37-49.

10 Kirchner C, Phillips B. Report of a survey of US low vision services. J Vis Impair Blind 1980;March:122-4.

11 Department of Health. Personal Social Services (31/3/94). London: $\mathrm{DoH}, 1994$. 
12 Scottish Education Department, Social Work Services Group (31/3/94). Edinburgh: SED, 1994.

13 Welsh Office (31/4/94). Cardiff: WO, 1994.

14 Northern Ireland Health and Social Services Board (31/3/94) Belfast: NIHSSB, 1994

15 Reidy A, Minassian DC, Vafidis G, et al. Prevalence of serious eye disease and visual impairment in a north London population: population based, cross sectional study. BM 1998;316:1643-6.

16 Wormald RPL, Wright LA, Courtney $P$, et al. Visual problems in the elderly population and implications for services. BM 1992;304:1226-9.

17 Wormald R, Evans J. Registration of blind and partially sighted people (editorial). Br J Ophthalmol 1994:78:733-4.

18 Harper R, Culham L, Dickinson C. Head mounted video magnification devices for low vision rehabilitation: a comparison with existing technology. Br J Ophthalmol 1999;83:495-500.
19 Silver J, Thomsitt J. Low-vision services in the United Kingdom. Health Trends 1977;9:73-5.

20 Evans J, Rooney C, Ashwood F, et al. Blindness and partial sight in England and Wales: April 1990-March 1991. Health Trends 1996;28:5-12.

21 Klein R, Klein BEK, Linton KLP, et al. The Beaver Dam Eye Study: Visual Acuity. Ophthalmology 1991:98:1310-15.

22 Shaw C. 1996-Based national population projections for the United Kingdom and constituent countries. Population Trends 1998;91:43-9.

23 Chong NHV, Bird ACB. Alternative therapies in exudative age related macular degeneration. Br J Ophthalmol 1998;82:1441-3.

24 Low Vision Services Consensus Group. A framework for low vision services in the United Kingdom. London: Royal National Institute for the Blind, 1999.

25 Royal College of Ophthalmologists. The provision of low vision care. London: RCO, 1998.

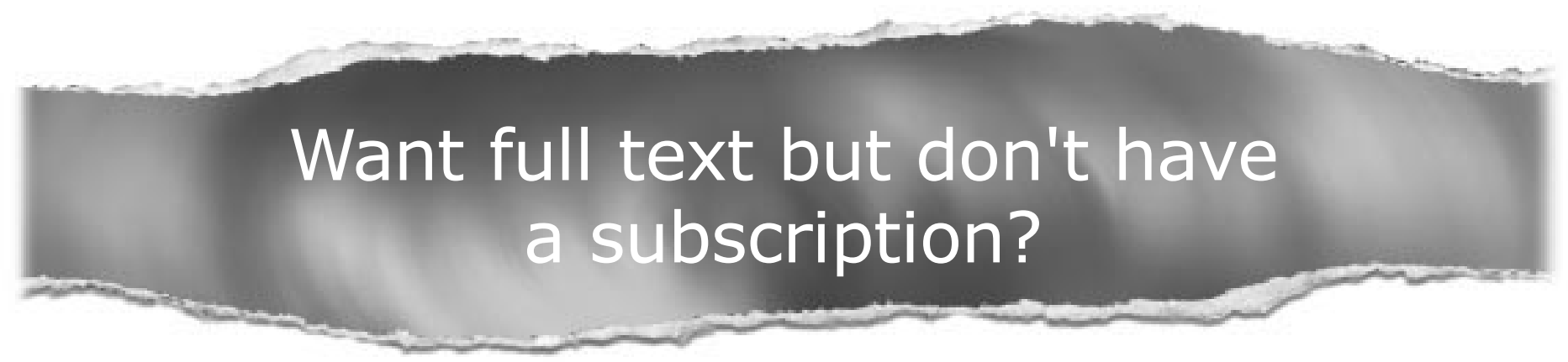

\section{Pay per view}

For just $\$ 8$ you can purchase the full text of individual articles using our secure online ordering service. You will have access to the full text of the relevant article for 48 hours during which time you may download and print the pdf file for personal use.

\section{www.bjophthalmol.com}

